See Article page 234 .

\section{Commentary: Right ventricle, right time}

Andrew M. Vekstein, MD, Joseph W. Turek, MD, PhD, and Nicholas D. Andersen, MD

Primary cardiac tumors are quite uncommon and are even more rarely found in the pediatric population and ventricular position. Patients may present with a combination of obstructive, embolic, and/or constitutional symptoms. A French series of 112 left atrial myxomas found that heart failure symptoms were the most frequent initial presentation $(43 \%)$, whereas syncope $(13 \%)$ and vague systemic symptoms such as fever $(20 \%)$ and weight loss $(18 \%)$ were less common. ${ }^{1}$ In the case of intraventricular cardiac masses, an exceptional diagnostic approach and, sometimes, a bit of luck are necessary to make the diagnosis before catastrophic complications, such as pulmonary emboli, stroke, and sudden cardiac death. Previous reports of obstructing right ventricular myxoma have had positive outcomes with prompt surgical resection. ${ }^{2}$

In the current issue of JTCVS Techniques, Mizrahi and colleagues $^{3}$ present the fortunate case of a healthy 16year-old female patient, with a remarkable family history of sudden cardiac death in multiple relatives, who initially presented with syncope in a relative hypovolemic state after blood donation. Echocardiogram ordered by her primary practitioner and subsequent magnetic resonance imaging revealed a $5 \times 3-\mathrm{cm}$ partially obstructing mass in the right ventricular outflow tract, which prompted emergent surgical resection via sternotomy and combination right atriotomy and pulmonary arteriotomy on cardiopulmonary

From the Division of Cardiovascular and Thoracic Surgery, Department of Surgery, Duke University Medical Center, Durham, NC.

Disclosures: The authors reported no conflicts of interest.

The Journal policy requires editors and reviewers to disclose conflicts of interest and to decline handling or reviewing manuscripts for which they may have a conflict of interest. The editors and reviewers of this article have no conflicts of interest.

Received for publication July 23, 2020; revisions received July 23, 2020; accepted for publication July 24, 2020; available ahead of print July 31, 2020.

Address for reprints: Nicholas D. Andersen, MD, Division of Cardiovascular and Thoracic Surgery, Duke Children's Pediatric \& Congenital Heart Center, 2301 Erwin Rd, DUMC 3474, Durham, NC 27710 (E-mail: nicholas.andersen@ duke.edu). JTCVS Techniques 2020;3:236-7

2666-2507

Copyright (c) 2020 The Authors. Published by Elsevier Inc. on behalf of The American Association for Thoracic Surgery. This is an open access article under the CC BY-NCND license (http://creativecommons.org/licenses/by-nc-nd/4.0/).

https://doi.org/10.1016/j.xjtc.2020.07.025

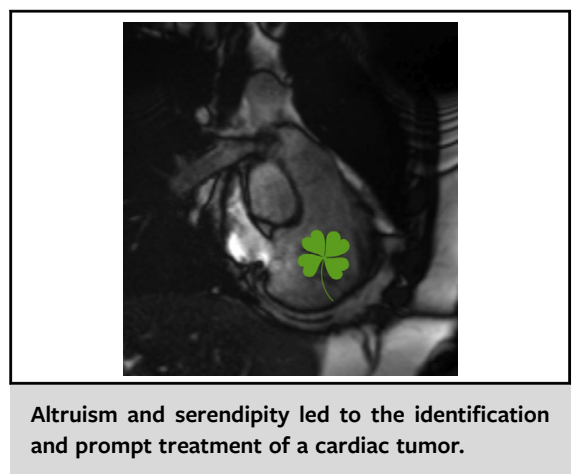

CENTRAL MESSAGE

A combination of fortunate

timing, collaborative diagnostic

approach, and prompt surgical

management can lead to excel-

lent outcomes in obstructing

cardiac myxoma in the pediatric

population.

bypass. The initial examining physicians and surgical team should both be commended for prompt diagnosis and operative intervention at the right time, at the right tertiary care institution.

Although not the first report of an obstructing right ventricular myxoma in a teenager, this case report is notable for 3 reasons: (1) it highlights a unique presentation of cardiac myxoma that required collaborative diagnosis with primary care and emergency providers, (2) it prompts discussion on the rare familial myxoma syndromes, and (3) it demonstrates a positive outcome with prompt surgical resection. As the authors describe, syncope after blood donation in a teenaged female patient is certainly not an uncommon event, and this patient could have been placed in the "horse" category of hypovolemic syncope. However, the nowadays not-guaranteed cardiac auscultation in the emergency department placed the patient on a prompt workup toward the "zebra" diagnosis of right ventricular myxoma. Although subsequent echocardiograms of alive family members did not reveal cardiac myxomas in this case, a total of 9 relatives with sudden or early cardiac death remains highly suspicious for a familial myxoma syndrome. Initially described by Dr Carney, for whom the syndrome is now named, a mutation in regulatory subunit PRKAR $1 \alpha$ of the protein kinase A gene leads to not only cardiac myxoma but also cutaneous myxoma and pigmented lesions, 
accompanied by endocrine anomalies. ${ }^{4}$ Other nonspecific familial myxoma syndromes have also been described. ${ }^{5}$ It is important for cardiac surgeons to be aware of these syndromes to provide proper counseling and referral for patients and their family members, as the authors did.

The study by Mizrahi and colleagues ${ }^{3}$ can guide not only cardiac surgical but also institutional practice for the workup and treatment of rare cardiac tumors. A high index of suspicion paired with proper examination led to the correct referral to a center with congenital cardiac surgical expertise and exceptionally swift workup, with the patient moving to the operating room directly from magnetic resonance imaging. Although smaller right ventricular masses may be able to be resected through the right atrium alone, opening the main pulmonary artery allows safe resection of larger masses without disrupting the tricuspid valve apparatus and without adding significant risk or cardiopulmonary bypass time. The correct systematic approach can lead to exceptional outcomes for a rare intra-cardiac tumor in the pediatric population.

\section{References}

1. Diaz A, Di Salvo C, Lawrence D, Hayward M. Left atrial and right ventricular myxoma: an uncommon presentation of a rare tumour. Interact Cardiovasc Thorac Surg. 2011;12:622-5.

2. Kern JH, Aguilera FA, Carlson DL, Galantowicz M. Right ventricular myxoma obstructing the right ventricular outflow tract. Circulation. 2000;102: e14-5.

3. Mizrahi M, Hasbani K, Fraser CD, Beckerman Z. Unusual presentation of an obstructing cardiac myxoma. J Thorac Cardiovasc Surg Tech. 2020;3:234-5.

4. Shetty Roy AN, Radin M, Sarabi D, Shaoulian E. Familial recurrent atrial myxoma: Carney's complex. Clin Cardiol. 2011;34:83-6.

5. van Gelder HM, O’Brien DJ, Staples ED, Alexander JA. Familial cardiac myxoma. Ann Thorac Surg. 1992;53:419-24. 